\title{
Short- and long-term effects of tailored information versus general information on determinants and intentions related to early detection of cancer
}

Citation for published version (APA):

de Nooijer, J. M., Lechner, E. H. S., Candel, M. J. J. M., \& de Vries, H. (2004). Short- and long-term effects of tailored information versus general information on determinants and intentions related to early detection of cancer. Preventive Medicine, 38(6), 694-703. https://doi.org/10.1016/j.ypmed.2003.12.016

Document status and date:

Published: 01/01/2004

DOI:

10.1016/j.ypmed.2003.12.016

Document Version:

Publisher's PDF, also known as Version of record

\section{Document license:}

Taverne

Please check the document version of this publication:

- A submitted manuscript is the version of the article upon submission and before peer-review. There can be important differences between the submitted version and the official published version of record.

People interested in the research are advised to contact the author for the final version of the publication, or visit the DOI to the publisher's website.

- The final author version and the galley proof are versions of the publication after peer review.

- The final published version features the final layout of the paper including the volume, issue and page numbers.

Link to publication

\footnotetext{
General rights rights.

- You may freely distribute the URL identifying the publication in the public portal. please follow below link for the End User Agreement:

www.umlib.nl/taverne-license

Take down policy

If you believe that this document breaches copyright please contact us at:

repository@maastrichtuniversity.nl

providing details and we will investigate your claim.
}

Copyright and moral rights for the publications made accessible in the public portal are retained by the authors and/or other copyright owners and it is a condition of accessing publications that users recognise and abide by the legal requirements associated with these

- Users may download and print one copy of any publication from the public portal for the purpose of private study or research.

- You may not further distribute the material or use it for any profit-making activity or commercial gain

If the publication is distributed under the terms of Article $25 \mathrm{fa}$ of the Dutch Copyright Act, indicated by the "Taverne" license above, 


\title{
Short- and long-term effects of tailored information versus general information on determinants and intentions related to early detection of cancer
}

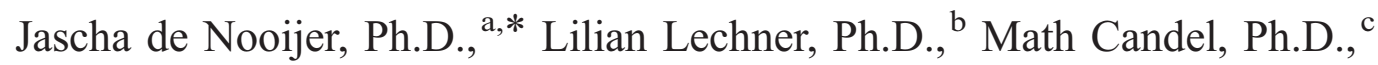 \\ and Hein de Vries, Ph.D. ${ }^{\text {a }}$ \\ ${ }^{a}$ Department of Health Promotion and Health Education, Maastricht University, Maastricht, The Netherlands \\ ${ }^{\mathrm{b}}$ Department of Psychology, Open University, Heerlen, The Netherlands \\ ${ }^{\mathrm{c}}$ Department of Methodology and Statistics, Maastricht University, Maastricht, The Netherlands
}

Available online 27 February 2004

\begin{abstract}
Background. Since it is widely accepted that the earlier cancer is detected, the better the chances of treatment and survival, people should be encouraged to create positive intentions toward early detection of several types of cancer, for instance, skin cancer, breast cancer, and colon cancer. This can be done by being alert to the warning signs of cancer and seeking help once a cancer symptom is detected.

Methods. A randomized controlled study $(n=1,500)$ assessed the effects of computer-tailored information and general information on determinants and intentions to engage in early detection behaviors (i.e., passive detection and help seeking) compared with those in a control group. Possible negative side effects, like increased chronic fear of cancer and more fatalistic attitudes toward cancer, were studied as well.

Results. Shortly after the intervention, differences between the study groups were found in intention, several social psychological determinants, and knowledge. Six months after the intervention, there were still differences between the tailored information group and the control group in intentions toward help seeking. Neither of the interventions resulted in increased chronic fear nor more fatalistic attitudes toward cancer.

Conclusions. It is concluded that there were positive effects of the tailored intervention on determinants, passive detection, and help-seeking intentions in the short-term, but additional research is needed to assess ways of maintaining these effects in the long-term.
\end{abstract}

(C) 2004 The Institute For Cancer Prevention and Elsevier Inc. All rights reserved.

Keywords: Tailored information; General information; Cancer

\section{Introduction}

It is widely accepted that the earlier cancer is detected, the better the chances of treatment and survival [1]. In practice, however, cancer detection and diagnosis are often subject to delays [2-6]. Therefore, people should be encouraged to engage in early detection behaviors, such as being attentive to cancer symptoms (see Table 1), selfexamination, seeking medical help when symptoms are detected, and participating in screening programs. According to Qin et al. [7], cancer can be divided into three anatomical categories: (1) cancers of the superficial organs,

* Corresponding author. Department of Health Promotion and Health Education, Maastricht University, PO Box 616, Maastricht, MD 6200, The Netherlands. Telefax: +31-43-3671032.

E-mail address: j.denooijer@gvo.unimaas.nl (J. de Nooijer). such as skin, breast, and testis, which can be detected by looking for lumps, ulcerations or moles, or by palpation; (2) cancers of the hollow organs, such as urinary bladder, lungs, etc., which can be detected by, for instance, blood loss; and (3) cancer of deep, solid organs, which does not give any signals in the early development of the cancer and which cannot be detected by palpation. Malignancies of these organs rarely give symptoms in the early stages, and can only be detected by medical tests, such as X-ray, CT scans, and blood tests. The focus of the present study is therefore on types of cancer included in the first two categories.

Many programs have been developed to stimulate people to perform breast self-examination (BSE) or testicular selfexamination (TSE) and to participate in screening programs for breast and cervical cancer (e.g., [8-14]). Far less has been done to enhance attentiveness to general cancer symptoms and to seeking help for these symptoms. A study in 
Table 1

Warning signs of cancer [56]

\begin{tabular}{ll}
\hline 1 & Nagging cough or hoarseness \\
2 & Sores that do not heal \\
3 & Obvious changes in warts or moles \\
4 & Indigestion or difficulty swallowing \\
5 & Swellings or lumps in breast or elsewhere \\
6 & Unusual bleeding or discharge \\
7 & Changes in bowel or bladder habits \\
8 & Unusual weight loss \\
\hline
\end{tabular}

Sweden attempted to shorten patient delay by informing patients by letter about the symptoms of common forms of cancer. Patients were invited to visit health centers if the symptoms mentioned in the letter were observed [15]. This resulted in 234 visits and the detection of 15 cancers, of which 13 were localized. Another study was undertaken to improve specifically the prognosis of melanoma by providing the public with information on features of early melanoma, and to encourage people to consult a physician if they recognized such lesions on their skin [5]. Very promising results were obtained within a period of 6 months after the intervention: the proportion of patients diagnosed with 'good prognosis' had increased from $38 \%$ to $62 \%$, while the proportion of patients with 'poor prognosis' had decreased from $34 \%$ to $15 \%$. Unfortunately, no control groups were included in either of these studies, so the value of the conclusions on patient delay or prognosis was limited. In The Netherlands, the Dutch Cancer Society has developed several brochures informing the general public about early detection of cancer, including the 'warning signs of cancer', BSE, TSE, and participating in screening programs. Furthermore, in 1997, a mass media campaign was launched within the framework of the European Week Against Cancer, attempting to get people to pay attention to symptoms of forms of cancer common among men [16]. Unfortunately, these interventions were not evaluated for their effects.

It is often questioned whether interventions on early detection of cancer may cause fear, or that certain information may result in unnecessary worries about a particular complaint or a particular diagnosis. Fear may lead to different coping styles, for instance, by avoiding the threatening situation [17]. This might mean that people who cannot cope with the fear associated with the detection of cancer, and who have little trust in the effectiveness of medical treatment, respond with fatalistic opinions toward cancer, such as, 'if you find a cancer symptom, it's too late to do anything about it anyway,' and hence do not engage in early detection behaviors [18]. In the Swedish study, the information did not cause anxiety [15], and the same was found in studies providing information about breast selfexamination, testicular cancer, and testicular self-examination $[8,19,20]$. Nevertheless, in developing health education interventions on early detection of cancer, the undesirable side effect of fear and unnecessary worries should be very carefully taken into consideration.
A promising and relatively new approach in health education is computerized tailoring, which adapts health education messages to the characteristics, needs, and interests of the recipient [21-23]. This leads to more personally relevant information, which is more likely to be thoughtfully considered [24], and is therefore thought to be more effective in changing determinants and behaviors than generic information. Computerized tailoring has been shown to change intentions and behaviors, such as reducing fat intake and stimulating fruit and vegetable intake $[25,26]$, smoking cessation [27,28], losing weight [29], promoting physical activity [30], participating in mammography screening $[10,11]$ and PAP test [14]. Computerized tailoring focuses on individuals. Messages are based on individual self-reported behavior and beliefs [31].

If the goal of an intervention is to encourage healthy behavior, it is necessary to know what the underlying factors are, which decide whether a person will engage or not engage in that particular behavior [32]. We used the Attitude-Social Influence-Self Efficacy (ASE) model [33,34], which can be regarded as an extended version of the Theory of Planned Behavior [35]. This model distinguishes three determinants influencing people's motivation to perform a particular behavior. Intention, on its turn, influences actual behavior (Fig. 1). The three main determinants have an impact on behavior through the influence on intention. The first determinant, attitude, refers to a person's beliefs about the behavior, for instance, the advantages or disadvantages he or she expects from performing the behavior. The attitude concept has recently been supplemented with two affective components [36]. The first is anticipated regret, which is the feeling of regret someone expects to experience afterwards if he or she chooses not to perform the behavior. The second is moral obligation, which refers to a personal belief about what ought to be done. Behavior or intentions toward behavior are also influenced by what important people in someone's environment do or think, which refers to the second determinant, social influence. The third determinant is self-efficacy, that is, someone's belief in his or her own capability to perform the behavior. There are several differences between the ASE model and the TPB in the constructs and the way they are measured. First, the ASE model added anticipated regret and moral obligation. These factors have proven to be significant predictors of early detection behaviors [36-38]. Second, in

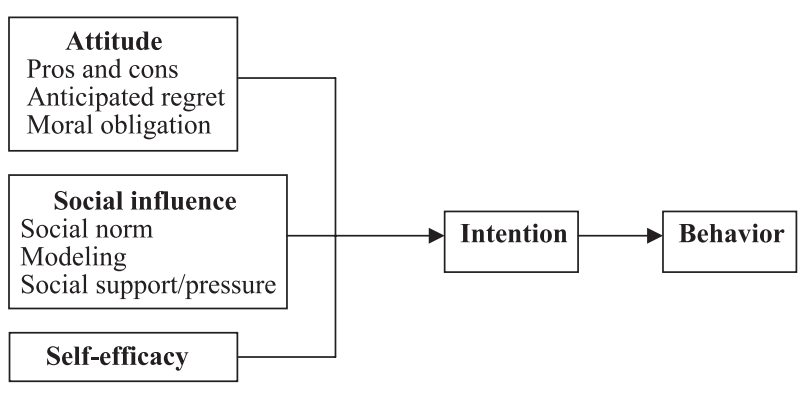

Fig. 1. The Attitude-Social Influence-Self Efficacy model. 
the TPB, social influence is assessed by the social norm (i.e., what other people think you should do). In the ASE model, as additional aspects of social influence, the modeling concept and social support/pressure were added. Third, the selfefficacy concept of Bandura was included in the ASE model, while TPB measured perceived behavioral control. The models differ from each other in the way constructs are measured, whereas TPB uses multiplicative functions to assess attitudes (belief, evaluation), social norm (norm, motivation to comply), and self-efficacy (control beliefs, perceived power); ASE does not. The ASE has proven to be a useful model in predicting several behaviors related to the primary prevention of cancer and coronary heart disease [39-42], and also to the secondary prevention of cancer [3638]. By including these additional concepts, we expect a valuable contribution of the ASE model in the present study.

So far, no tailored interventions have been developed or evaluated to motivate asymptomatic people to engage in early cancer detection behaviors, except for those stimulating women to have a mammography. Therefore, a randomized controlled study with a pretest and two post-tests was conducted to test two different interventions: a computerized tailored intervention and the standard general information currently provided by the Dutch Cancer Society to encourage the Dutch adult population to form positive intentions. We studied the effects of the two interventions on intentions, social psychological determinants, and knowledge, immediately after the intervention and after 6 months, and compared these with the same parameters in a control group that received no information. Intention was chosen as an outcome measure, since 6 months is too short to assess actual detection of possible cancer symptoms in a general population and their response once a symptom is detected. The intention toward two behaviors was distinguished: (1) passive detection, which may be described as becoming aware of cancer symptoms, but does not require any concrete action to be undertaken, and (2) consulting a physician once a possible cancer symptom was detected. If a possible cancer symptom is not followed up by medical consultation, the detection is in fact useless and the cancer detection process will be delayed. It was hypothesized that the changes in social psychological determinants and intentions would be significantly more positive for the recipients of the tailored information. Furthermore, we hypothesized that the tailored information would not increase chronic fear of cancer or fatalistic attitudes toward cancer.

\section{Methods}

\section{Study design and procedures}

A randomized controlled study with a pretest and two post-tests to evaluate the impact of a computerized tailored intervention on early detection of cancer was conducted among 1,855 Dutch adults. Subjects were recruited in Janu- ary 1999 by a short announcement in local door-to-door newspapers throughout The Netherlands, and in one national newspaper. Those interested in participation were asked to register by telephone or e-mail and they were told that they were participating in a study on the effects of different kinds of information about early detection of cancer. Subjects were randomly assigned to the tailored information group, the general information group, or the control group. After registration by telephone or e-mail, subjects received the first questionnaire (T0) together with information about the study procedures, and an informed consent form according to regulations of the Dutch government on medical studies with human subjects. Subjects who were cancer patients at T0 were excluded from all analyses, but for ethical reasons, they remained included in the sample, and since they had agreed to participate in the study, they received information and the first post-test. No other inclusion criteria were used. The tailored information and the general information were mailed to the subjects within 3 weeks after the first questionnaire had been returned. The control group did not receive any information, but they were given the general information after completion of the study. Three weeks after the intervention, and for the control group 6 weeks after the first questionnaire, all subjects received a second questionnaire (T1). All subjects whose second questionnaire was received and who did not suffer from cancer at $\mathrm{T} 0$ were approached by telephone for a short interview on their behavior and intentions regarding early detection 6 months after the intervention (T2). The university's medical ethics committee approved the study.

\section{Questionnaires}

The ASE model was used as a framework for the questionnaires. Intentions regarding early detection of cancer were measured at $\mathrm{T} 0$ (screening questionnaire and pretest) and $\mathrm{T} 1$ (first post-test) by written questionnaires, and at $\mathrm{T} 2$ (second post-test) by a telephone interview. At T0 and T1, social psychological determinants of early detection behaviors were assessed as well. The different concepts assessed are described below. Cronbach's alphas, Pearson correlations, and examples of each concept are presented in Table 2.

Intention toward paying attention to a possible cancer symptom, and the intention to consult a physician once a possible cancer symptom was detected, was assessed using one item for each of the 14 cancer symptoms.

Attitudes toward early detection behaviors were assessed using several concepts:

Advantages were assessed by four items for passive detection, and by four items for seeking help.

Disadvantages were assessed by three items for passive detection, and five items for help seeking.

Moral obligation was assessed using one item for passive detection, and one item for help seeking.

Anticipated regret was assessed by one item for passive detection, and two items for help-seeking behavior. 
Table 2

Description of the various concepts assessed, and Cronbach's alpha/Pearson correlation, and examples of the questions

\begin{tabular}{|c|c|c|}
\hline $\begin{array}{l}\text { Concepts } \\
\text { (number of items) }\end{array}$ & $\begin{array}{l}\text { Cronbach's } \\
\alpha / \text { Pearson } r\end{array}$ & $\begin{array}{l}\text { Examples of the questions, answering } \\
\text { options, and range }\end{array}$ \\
\hline \multicolumn{3}{|l|}{ Passive detection } \\
\hline $\begin{array}{l}\text { Attitude-pros } \\
\text { (4) }\end{array}$ & $\alpha=0.64$ & $\begin{array}{l}\text { To what extent do you think paying } \\
\text { attention to cancer symptoms is } \\
\text { useful? not useful at all (1) to very } \\
\text { useful (4) }\end{array}$ \\
\hline $\begin{array}{l}\text { Attitude-cons } \\
\text { (3) }\end{array}$ & $\alpha=0.75$ & $\begin{array}{l}\text { To what extent do you think paying } \\
\text { attention to cancer symptoms is } \\
\text { frightening? not frightening at all (1) } \\
\text { to very frightening (4) }\end{array}$ \\
\hline $\begin{array}{l}\text { Moral obligation } \\
\text { (1) }\end{array}$ & - & $\begin{array}{l}\text { To what extent do you consider it to } \\
\text { be an obligation to yourself and your } \\
\text { family to pay attention to cancer } \\
\text { symptoms? no obligation at all (1) to } \\
\text { much obligation (4) }\end{array}$ \\
\hline $\begin{array}{l}\text { Anticipated } \\
\text { regret (1) }\end{array}$ & - & $\begin{array}{l}\text { To what extent would you feel regret } \\
\text { that you had not been more attentive } \\
\text { if you did not pay attention to cancer } \\
\text { symptoms and cancer would be } \\
\text { diagnosed afterwards? no regret (1) } \\
\text { to much regret (4) }\end{array}$ \\
\hline $\begin{array}{l}\text { Social norm } \\
\text { (4) }\end{array}$ & $\alpha=0.63$ & $\begin{array}{l}\text { Does your partner think you should } \\
\text { pay attention to cancer symptoms? } \\
\text { certainly not }(-2) \text { to certainly yes }(2)\end{array}$ \\
\hline Modeling (1) & - & $\begin{array}{l}\text { How many people in your immediate } \\
\text { environment pay attention to cancer } \\
\text { symptoms? almost none (1) to almost } \\
\text { all (5) }\end{array}$ \\
\hline $\begin{array}{l}\text { Self-efficacy } \\
\text { ability } \\
\text { (SE I) (1) }\end{array}$ & - & $\begin{array}{l}\text { Do you think you are able to pay } \\
\text { attention to cancer symptoms? } \\
\text { certainly not }(-2) \text { to certainly yes }(2)\end{array}$ \\
\hline $\begin{array}{l}\text { Self-efficacy } \\
\text { difficulties } \\
\text { (SE II) (1) }\end{array}$ & - & $\begin{array}{l}\text { To what extent do you find it difficult } \\
\text { to pay attention to cancer symptoms? } \\
\text { very difficult }(-2) \text { to very easy (2) }\end{array}$ \\
\hline Intention (14) & $\alpha=0.93$ & $\begin{array}{l}\text { To what extent do you intend to pay } \\
\text { attention to each cancer symptom? } \\
\text { certainly not }(-3) \text { to certainly yes }(3)\end{array}$ \\
\hline \multicolumn{3}{|l|}{ Help seeking } \\
\hline $\begin{array}{l}\text { Attitude-pros } \\
\text { (4) }\end{array}$ & $\alpha=0.57$ & $\begin{array}{l}\text { To what extent do you expect } \\
\text { certainty about your health if you } \\
\text { seek help for cancer symptoms? } \\
\text { no certainty at all (1) to much } \\
\text { certainty ( } 4 \text { ) }\end{array}$ \\
\hline $\begin{array}{l}\text { Attitude-cons } \\
\text { (5) }\end{array}$ & $\alpha=0.78$ & $\begin{array}{l}\text { To what extent is it unpleasant for } \\
\text { you to pay attention to possible } \\
\text { cancer symptoms? not unpleasant at } \\
\text { all (1) to very unpleasant (4) }\end{array}$ \\
\hline $\begin{array}{l}\text { Moral obligation } \\
\text { (1) }\end{array}$ & - & $\begin{array}{l}\text { To what extent do you consider it to } \\
\text { be an obligation to yourself and your } \\
\text { family to seek help for cancer } \\
\text { symptoms? no obligation at all (1) } \\
\text { to much obligation (4) }\end{array}$ \\
\hline $\begin{array}{l}\text { Anticipated regret } \\
\text { (2) }\end{array}$ & $r=0.65$ & $\begin{array}{l}\text { To what extent would you feel regret } \\
\text { that you did not respond more } \\
\text { appropriately on the detection of a } \\
\text { cancer symptom if you delay in } \\
\text { seeking help for cancer symptoms } \\
\text { and cancer would be diagnosed } \\
\text { afterwards? no regret (1) to much } \\
\text { regret (4) }\end{array}$ \\
\hline
\end{tabular}

Table 2 (continued)

\begin{tabular}{|c|c|c|}
\hline $\begin{array}{l}\text { Concepts } \\
\text { (number of items) }\end{array}$ & $\begin{array}{l}\text { Cronbach's } \\
\alpha / \text { Pearson } r\end{array}$ & $\begin{array}{l}\text { Examples of the questions, answering } \\
\text { options, and range }\end{array}$ \\
\hline \multicolumn{3}{|l|}{ Help seeking } \\
\hline Social norm (4) & $\alpha=0.60$ & $\begin{array}{l}\text { Does your partner think you should } \\
\text { seek help for cancer symptoms? } \\
\text { certainly not }(-2) \text { to certainly yes } \\
\text { (2) }\end{array}$ \\
\hline Modeling (1) & - & $\begin{array}{l}\text { How many people in your } \\
\text { immediate environment seek help } \\
\text { for cancer symptoms? almost none } \\
\text { (1) to almost all (5) }\end{array}$ \\
\hline $\begin{array}{l}\text { Self-efficacy } \\
\text { ability } \\
\quad \text { (SE III) (1) }\end{array}$ & - & $\begin{array}{l}\text { Do you think you are able to seek } \\
\text { help for cancer symptoms? certainly } \\
\text { not }(-2) \text { to certainly yes }(2)\end{array}$ \\
\hline $\begin{array}{l}\text { Self-efficacy } \\
\text { difficulties } \\
\text { (SE IV) (1) }\end{array}$ & - & $\begin{array}{l}\text { To what extent do you find it } \\
\text { difficult to seek help for cancer } \\
\text { symptoms? very difficult }(-2) \text { to } \\
\text { very easy (2) }\end{array}$ \\
\hline $\begin{array}{l}\text { Self-efficacy } \\
\text { situations } \\
\text { (SE V) (4) }\end{array}$ & $\alpha=0.88$ & $\begin{array}{l}\text { Do you think you are able to seek } \\
\text { help when you doubt whether a } \\
\text { symptom is a cancer symptom? } \\
\text { certainly not }(-2) \text { to certainly yes } \\
\text { (2) }\end{array}$ \\
\hline Intention (14) & $\alpha=0.93$ & $\begin{array}{l}\text { To what extent do you intend to } \\
\text { seek help for each cancer } \\
\text { symptom? certainly not }(-3) \text { to } \\
\text { certainly yes ( } 3)\end{array}$ \\
\hline \multicolumn{3}{|l|}{ General concepts } \\
\hline Knowledge (15) & - & $\begin{array}{l}\text { Do you think this symptom is a } \\
\text { possible cancer symptom? certainly } \\
\text { not }(-2) \text { to certainly yes }(2)\end{array}$ \\
\hline Fatalism (3) & $\alpha=0.70$ & $\begin{array}{l}\text { To what extent do you agree with } \\
\text { the following statements: If cancer } \\
\text { is detected in the early stages, } \\
\text { misery is prolonged. certainly } \\
\text { disagree }(-2) \text { to certainly agree } \\
\text { (2) }\end{array}$ \\
\hline Fear (5) & $\alpha=0.72$ & $\begin{array}{l}\text { How scared are you of getting } \\
\text { cancer? not at all (1) to very scared } \\
\text { (5) }\end{array}$ \\
\hline
\end{tabular}

Social influence was assessed by two concepts:

Social norm of the partner, family members, friends, and the family physician was assessed by four items on passive detection, and four items on help seeking.

Modeling was assessed by one item for both passive detection, and help seeking.

Self-efficacy regarding passive detection was assessed by one item referring to the respondent's general expected ability to pay attention to cancer symptoms, and one item on the extent to which the respondent found it difficult to pay attention to cancer symptoms. Self-efficacy regarding seeking help for possible cancer symptoms was assessed by one item referring to the respondent's general expected ability to seek help for cancer symptoms, and one item regarding the extent to which the respondent found it difficult to seek help for 
cancer symptoms. Furthermore, self-efficacy was assessed by four situational items, assessing whether the respondents were able to seek help in four different situations (when they doubted whether the symptom was a cancer symptom, when they expected the physician to think the complaint was not serious, when they themselves expected the complaint not to be serious, and when they experienced fear).

Three additional concepts that are possibly related to passive detection as well as to help-seeking behavior were assessed:

Knowledge was assessed by a 15 -item scale adapted from Berman and Wandersman's Knowledge of Cancer Warning Signs Inventory [43]. The scale consisted of 10 correct symptoms and 5 incorrect symptoms, assessing whether respondents were able to distinguish cancer symptoms from noncancer symptoms. For each symptom, respondents were asked to indicate on a 5point scale whether they thought these symptoms were possible cancer symptoms (very sure to very unsure). All items were dichotomized for the analysis into correct (i.e., sure or very sure for cancer symptoms, and unsure or very unsure for noncancer symptoms), or incorrect (all other answers). A total knowledge score was computed by adding all correct answers (range, 0-15).

Chronic fear of cancer was assessed using five items. The concept of chronic fear was based on a questionnaire by Jepson and Chaiken [44]. The 10-point scale was changed to a 5-point scale.

Fatalistic attitudes toward early detection were assessed by three items.

Demographic variables (sex, age, level of education, and marital status) were asked for, as well as whether respondents had ever had cancer or had experienced cancer in their immediate environment.

\section{The intervention}

Three elements are necessary to develop a computertailored intervention. First, a screening questionnaire that provides the data on which the tailored feedback will be based. In our study, the pretest (T0) was used as the screening questionnaire. Second, a message source file that contains feedback messages for all possible answers included in the screening questionnaire. Third, a computer program to connect the screening questionnaire and the message source file, to facilitate the combining of messages, and to print this as a personal letter.

The message source file contained messages tailored to the individual's knowledge of cancer symptoms and early detection intentions. Furthermore, messages were included on reasons for early detection of cancer, risk perception, social psychological determinants (attitudes, social influ- ence, and self-efficacy), fear of cancer, and fatalistic attitudes toward cancer (Table 3). The tailored information comprised approximately six to eight pages, depending on the messages. The content of the tailored letter and the process evaluation is described elsewhere [45].

The computer program connects the screening instrument with the right messages and generates the personal letters. The tailoring algorithms were logical statements ('if-then' statements) [31].

The general information that was used was one of the brochures on early detection currently used by the Dutch Cancer Society. The brochure contained information similar to that in the tailored information [46].

\section{Statistical analysis}

Respondents who completed the three questionnaires and who did not suffer from cancer at T0 were included in the analysis. Those who had had cancer in the past but did not suffer from cancer at $\mathrm{T} 0$ were included in the analysis, since they have a comparable or higher risk of developing a subsequent cancer than the general population. All analyses were done with SPSS.

Attrition was studied by logistic regression analysis with attrition as dependent variable and the demographics, social psychological variables, and condition as predictors. Chisquare tests and $F$ tests were performed to analyze whether significant differences were found in dropouts of the different study groups. Baseline characteristics between study groups were compared with Chi-square tests and $F$ tests.

Multivariate analyses of covariance were performed to determine differences in means between study groups regarding knowledge and social psychological determinants at $\mathrm{T} 1$, adjusting for preexisting knowledge, social psychological determinants, and the demographic variables (sex, age, educational level, having a partner, knowing someone with cancer in the immediate environment, and having had cancer in the past). We used Pillai's Trace, which is the most robust criterion to test the significance of the main effect [47]. If a main effect of the three study groups on knowledge and determinants was found in the multivariate

Table 3

Content of the tailored letter

\begin{tabular}{ll}
\hline Section 1: & $\begin{array}{l}\text { Introduction, importance of early detection, risk } \\
\text { perception } \\
\text { Knowledge about cancer symptoms and behavior } \\
\text { (passive detection and seeking medical help) }\end{array}$ \\
Section 3: & Attitudes \\
Section 4: & Social influences \\
Section 5: & Self-efficacy \\
Section 6: & Breast self-examination (only for women) \\
Section 7: & Participating in screening programs for breast cancer \\
& and cervix cancer (only for women) \\
Section 8: & Testicular self-examination (only for men) \\
Section 9: & Closing section, including a reference to the Dutch \\
& Cancer Society \\
\hline
\end{tabular}


test, univariate tests were performed for each of the dependent variables. Subsequently, pairwise comparisons were made between the three study groups for the variables that turned out to be significant in the univariate tests, employing the Bonferroni procedure (adjusted for three comparisons $\alpha=$ $0.05 / 3=0.0167)$.

To investigate the effects of the intervention on (1) passive detection and help-seeking intentions, (2) chronic fear of cancer, and (3) a fatalistic attitude toward cancer in the different study groups, differences between study groups at the first post-test (T1) and the second post-test (T2) were analyzed by repeated measures analyses of covariance, adjusting for the scores at the pretest (T0). In the case of a group-time interaction effect, indicating that the mean difference between the two post-tests depended on the study group, separate analyses of covariance were performed to study the effects on $\mathrm{T} 1$ and $\mathrm{T} 2$. The covariates included in this analysis were the intentions toward passive detection and seeking help, chronic fear of cancer, fatalistic attitude at the pretest (T0), sex, age, educational level, having a partner, knowing someone with cancer in the immediate environment, and having had cancer in the past. When a group effect was found, pairwise comparisons using Bonferroni (adjusted $\alpha=0.0167$ ) were performed to analyze differences between study groups, based on the estimated marginal means (i.e., corrected for the covariates). In the case of a group-time interaction effect, paired $t$ tests were also performed to compare means between $\mathrm{T} 1$ and $\mathrm{T} 2$ within each study group.

\section{Results}

\section{Respondents}

Of the initial 1,855 volunteer subjects, 1,500 met the criteria for being approached for the telephone questionnaire at T2 (i.e., having completed the written questionnaires at T0 and $\mathrm{T} 1$, not having cancer at T0, having a telephone, and having indicated at T0 that they were willing to participate in the telephone questionnaire). A total of 1,358 (73\%) subjects completed the telephone questionnaire, equally distributed across the tailored information group (32\%), the general information group (33\%), and the control group (35\%). Attrition analysis revealed that drop-outs less often had cancer in the past $(P<0.01)$, less often had a partner $(P<$ $0.001)$, more often were younger respondents $(P<0.01)$, perceived less advantages of paying attention to cancer symptoms $(P<0.05)$, and perceived more disadvantages of paying attention to cancer symptoms $(P<0.05)$, but no significant differences in the distribution of these variables were found between study groups.

The non-response consisted of 109 respondents who were not reached within the time available for the telephone questionnaire for various reasons (i.e., unanswered calls, answering machines, or appointments could not be made within the period available for data collection). In $2 \%$ of the cases, the subjects $(n=33)$ were reached, but the participant had no time to participate, had moved to another address, or was abroad.

The study population was predominantly female $(80 \%)$, on average 47 years old (SD 12.93), and most of them had a partner (79\%). Of the respondents, 36\% had completed primary school or basic vocational training, $35 \%$ had completed secondary vocational training or high school, and $29 \%$ had a higher vocational or university degree. Most respondents $(92 \%)$ had been confronted with someone with cancer in their immediate environment, while $11 \%$ of the respondents had suffered from cancer themselves at one point in their lives. No differences in demographics, social psychological variables, intentions, behaviors, knowledge of cancer symptoms, chronic fear of cancer, and fatalistic attitudes toward cancer at T0 between the study groups were found, with one exception. In the tailored group, 46 respondents $(8 \%)$ had had cancer in the past, in the general information group, $75(13 \%)$, and in the control group, 52 $(9 \%)\left(\chi^{2}=9.34, d f=2, P<0.05\right)$. No differences were found between age distribution between the three study groups ('young' $n=342$; 'middle' $n=710$; 'old' $n=$ $\left.658, \chi^{2}=1.23, d f=4, \mathrm{~ns}\right)$.

\section{Knowledge of cancer symptoms and determinants of early detection}

The effects of the intervention at the first post-test (T1) on knowledge of cancer symptoms and determinants were tested by multivariate analyses of covariance. The analyses were adjusted for preexisting knowledge, attitudes, social influences, self-efficacy expectations, and demographic variables (measured at T0).

Table 4 shows the significant values for each of the $F$ tests of the individual dependent values, as well as the mean scores of knowledge of cancer symptoms, determinants of passive detection and help-seeking behavior at the first posttest (T1), and tests of the pairwise differences in means between the study groups. A main effect of group was found by using Pillai's Trace $[F(36,2246)=3.98, P<0.001]$, which means that there was an overall effect of study group on all dependent variables (knowledge and determinants). The univariate test showed that the groups differed significantly for a large number of dependent variables (Table 4). Pairwise comparisons showed that the tailored information group had a significantly higher level of knowledge than the general information group and the control group, while the general information group knew more cancer symptoms than the control group. For passive detection, significant differences were found between study groups in most social psychological variables, except for disadvantages and moral obligation. Furthermore, for help seeking, significant differences were found for some of the social psychological variables, but not for moral obligation, modeling, and selfefficacy (difficulties and situations). 
Table 4

Knowledge and social psychological determinants of passive detection behavior and help-seeking behavior: range, mean scores (standard deviation) at the first post-test (T1), and analyses of variance results

\begin{tabular}{|c|c|c|c|c|c|c|}
\hline & Range & $\begin{array}{l}\text { Tailored } \\
\text { Information } \\
\text { (T) }(n=430)\end{array}$ & $\begin{array}{l}\text { General } \\
\text { information } \\
\text { (G) }(n=439)\end{array}$ & $\begin{array}{l}\text { Control } \\
\text { group (C) } \\
(n=462)\end{array}$ & $F$ & $\begin{array}{l}\text { Pairwise } \\
\text { comparisons, } \\
\alpha=0.0167\end{array}$ \\
\hline Knowledge & $(0,15)$ & $9.85(3.13)$ & $9.26(3.37)$ & $8.21(3.27)$ & $30.28 *$ & $\mathrm{~T}>\mathrm{G}>\mathrm{C}$ \\
\hline \multicolumn{7}{|l|}{ Passive detection } \\
\hline Attitude - advantages & $(1,4)$ & $3.18(0.50)$ & $3.13(0.52)$ & $3.07(0.48)$ & $11.70 *$ & $\mathrm{~T}>\mathrm{G}, \mathrm{C}$ \\
\hline Attitude - disadvantages & $(1,4)$ & $2.05(0.70)$ & $2.05(0.69)$ & $2.09(0.68)$ & $3.05 * *$ & ns \\
\hline Moral obligation & $(1,4)$ & $3.43(0.60)$ & $3.41(0.60)$ & $3.40(0.59)$ & 1.1 & ns \\
\hline Anticipated regret & $(1,4)$ & $3.58(0.51)$ & $3.52(0.78)$ & $3.48(0.72)$ & $4.78 * * *$ & $\mathrm{~T}>\mathrm{G}, \mathrm{C}$ \\
\hline Social norm & $(-2,2)$ & $1.45(0.59)$ & $1.42(0.58)$ & $1.38(0.61)$ & $5.01 * * *$ & $\mathrm{~T}>\mathrm{C}$ \\
\hline Modeling & $(1,5)$ & $1.95(2.00)$ & $1.76(1.94)$ & $1.67(1.83)$ & $4.75 * * *$ & $\mathrm{~T}>\mathrm{C}$ \\
\hline Self-efficacy ability & $(-2,2)$ & $0.60(0.95)$ & $0.48(1.03)$ & $0.31(1.01)$ & $15.38^{*}$ & $\mathrm{~T}>\mathrm{G}, \mathrm{C}$ \\
\hline Self-efficacy difficulties & $(-2,2)$ & $-0.16(0.83)$ & $-0.15(0.83)$ & $-0.32(0.78)$ & $8.95^{*}$ & $\mathrm{~T}, \mathrm{G}>\mathrm{C}$ \\
\hline \multicolumn{7}{|l|}{ Help seeking } \\
\hline Attitude_-advantages & $(1,4)$ & $3.13(0.47)$ & $3.06(0.49)$ & $3.00(0.46)$ & $15.94^{*}$ & $\mathrm{~T}>\mathrm{G}, \mathrm{C}$ \\
\hline Attitude - disadvantages & $(1,4)$ & $2.08(0.64)$ & $2.16(0.66)$ & $2.11(0.61)$ & $4.01 * *$ & $\mathrm{~T}<\mathrm{G}$ \\
\hline Moral obligation & $(1,4)$ & $3.44(0.55)$ & $3.41(0.57)$ & $3.41(0.55)$ & 1.09 & ns \\
\hline Anticipated regret & $(1,4)$ & $3.41(0.68)$ & $3.36(0.76)$ & $3.32(0.70)$ & $4.47 * *$ & $\mathrm{~T}>\mathrm{G}, \mathrm{C}$ \\
\hline Social norm & $(-2,2)$ & $1.67(0.47)$ & $1.65(0.44)$ & $1.63(0.48)$ & $5.37 * * *$ & $\mathrm{~T}>\mathrm{C}$ \\
\hline Modeling & $(1,4)$ & $2.31(2.18)$ & $2.28(2.11)$ & $2.15(2.11)$ & 1.28 & ns \\
\hline Self-efficacy ability & $(-2,2)$ & $1.60(0.62)$ & $1.60(0.60)$ & $1.54(0.65)$ & $3.24 * *$ & $\mathrm{~T}>\mathrm{C}$ \\
\hline Self-efficacy difficulties & $(-2,2)$ & $0.31(1.06)$ & $0.23(1.04)$ & $0.26(1.07)$ & 2.15 & ns \\
\hline Self-efficacy situations & $(-2,2)$ & $1.25(0.73)$ & $1.24(0.73)$ & $1.22(0.76)$ & 2.34 & ns \\
\hline
\end{tabular}

Note. All analyses are based on estimated marginal means.

ns-not significant.

$* P<0.001$.

$* * P<0.05$.

$* * * P<0.01$

\section{Passive detection and help-seeking intentions}

Effects of the interventions on intentions were measured twice: 3 weeks after the intervention (T1) and 6 months after the intervention (T2). Table 5 lists the mean scores and standard deviations of the intentions to engage in passive detection and help-seeking behavior at T0, T1, and T2. Repeated measures analyses of covariance showed significant group-time interactions for the passive detection intention $[F(2,1289)=18.89, P<0.001]$, and for the help-seeking intention $[F(2,1288)=14.53, P<0.001]$. This indicates significant differences between study groups in changes in intentions between $\mathrm{T} 1$ and $\mathrm{T} 2$. Table 5 reveals that the higher intention scores for passive detection as well as for helpseeking behavior in the tailored information group increased somewhat between T1 and T2 $(T=-2.60, d f=434, P<0.01$ for passive detection intention and $T=-2.94, d f=434 P<$ 0.01 for help-seeking intention), while the lower scores of the general information and control groups increased considerably (general information group: $T=-7.03, d f=446, P<$ 0.001 for passive detection intention, and $T=-6.80, d f=$ 445, $P<0.001$ for help-seeking intention; control group: $T=$ $-11.17, d f=463, P<0.001$ for passive detection intention, and $T=-9.64, d f=464, P<0.001$ for help-seeking intention).

To test whether mean scores in intentions toward passive detection differed for the two post-tests, separate analyses of covariance were performed at T1 and T2. At T1, a significant group effect was found regarding passive detection intention $[F(2,1290)=53.58, P<0.001]$. Pairwise comparisons showed significant differences in intention scores toward passive detection for the three groups (Table 5). At T2, the significant group effect remained $[F(2,1299)=5.90, P<.01]$. Pairwise comparison showed a significant difference in the mean score between the tailored information group and the control group on the intention to engage in passive detection.

Table 5

Mean (standard deviation) of passive detection intention (range, $-3,3)$ and help-seeking intention (range, $-3,3$ ) at pretest (T0), first post-test (T1), and second post-test (T2)

\begin{tabular}{lllll}
\hline $\begin{array}{l}\text { Tailored } \\
\text { information } \\
(\mathrm{T})(n=434)\end{array}$ & $\begin{array}{l}\text { General } \\
\text { information } \\
(\mathrm{G})(n=446)\end{array}$ & $\begin{array}{l}\text { Control } \\
\text { group (C) } \\
(n=465)\end{array}$ & $\begin{array}{l}\text { Pairwise } \\
\text { comparisons, } \\
\alpha=0.0167\end{array}$ \\
\hline \multicolumn{2}{l}{$\begin{array}{l}\text { Passive detection intention } \\
\mathrm{T} 0\end{array} \quad 1.42(1.01)$} & $1.48(1.06)$ & $1.50(0.92)$ & - \\
$\mathrm{T} 1$ & $1.95(0.87)$ & $1.78(0.91)$ & $1.52(0.89)$ & $\mathrm{T}>\mathrm{G}>\mathrm{C}$ \\
$\mathrm{T} 2$ & $2.05(0.81)$ & $2.05(0.83)$ & $1.96(0.80)$ & $\mathrm{T}>\mathrm{C}$ \\
& & & & \\
Help-seeking intention & & & \\
$\mathrm{T} 0$ & $1.57(0.91)$ & $1.62(0.92)$ & $1.67(0.83)$ & - \\
$\mathrm{T} 1$ & $2.03(0.79)$ & $1.86(0.83)$ & $1.63(0.87)$ & $\mathrm{T}>\mathrm{G}>\mathrm{C}$ \\
$\mathrm{T} 2$ & $2.13(0.76)$ & $2.09(0.80)$ & $1.99(0.75)$ & $\mathrm{T}>\mathrm{G}, \mathrm{C}$ \\
\hline
\end{tabular}

Note. All analyses are based on estimated marginal means. 
Likewise, significant differences in help-seeking intentions were found between the three study groups at T1 $[F(2,1289)=60.71, P<0.001]$ and at $\mathrm{T} 2[F(2,1298)=$ $11.81, P<0.001]$. At T1, as well as at T2, pairwise comparisons showed significant differences between the three study groups in scores on the intention to engage in helpseeking behavior (Table 5).

\section{Chronic fear of cancer and fatalistic attitudes toward early detection of cancer}

To determine whether the intervention to motivate people to engage in early detection behavior resulted in negative side effects, such as increased chronic fear of cancer and more fatalistic attitudes, repeated measures analyses of covariance were performed. No interactions were found between time and group $[F(2,1241)=0.67, P=0.51$ for fear, and $F(2,1286)=0.20, P=0.82$ for fatalistic attitudes]. This implies that the mean differences at the two post-tests did not differ significantly between groups. For fatalistic attitudes toward early detection, a group effect was found for the average of T1 and T2 $[F=(2,1286)=3.56, P<$ 0.05]. However, pairwise comparisons did not reveal any differences between the study groups in the mean scores of $\mathrm{T} 1$ and T2. No group effect was found for chronic fear of cancer, which means that there were no differences between the study groups in scores on fear of cancer.

\section{Discussion}

The present study tested the impact of a computertailored intervention in encouraging people to form positive intentions toward early detection behaviors. Short-term effects showed that the tailored information group had more knowledge of cancer symptoms, more positive expectations of the advantages of early detection behaviors, and higher self-efficacy expectations toward passive detection than the control group and/or the general information group. Additionally, the recipients of the tailored information expressed more positive intentions toward engaging in passive detection and help-seeking behavior than the general information group and the control group after 3 weeks. After 6 months, significant differences in intention to seek help remained between the tailored information group and both of the other groups. The tailored information group had more positive intentions toward passive detection than the control group, but the general information group did not differ from either of the other groups. Although differences seem rather small, on a population level, these small differences could have an impact. If an only moderate effect (people are more attentive in intent to seek help a little sooner) can be achieved with a large target population, the total absolute effect (the amount of cancers detected early with a subsequent more successful treatment) can be big. This allows us to conclude that information tailored to the individual seems more effective than general information, which is in line with the findings of previous studies on tailored health information [10,11,25-30,48].

Furthermore, we found a lack of change in the dependent variables between $\mathrm{T} 1$ and $\mathrm{T} 2$ in the tailored information group, but additional effects in the general information group and the control group. It is possible that a ceiling effect occurred in the tailored information group. This means that it was more difficult to achieve an improvement in scores on intentions or behaviors that were already high at $\mathrm{T} 1$ than in scores that were lower at T1 [49].

The intervention did not lead to increased chronic fear of cancer, or to increased fatalistic attitudes toward cancer. This is consistent with results of a Swedish study on informing people about cancer symptoms and stimulating them to seek help [15]. Both the tailored information and the general information paid specific attention to the fear that may be caused by detecting a possible cancer symptom. Both types of information emphasized that delay does not lead to less fear, and that the fear may be taken away by consulting a physician. Another explanation can be found in Rogers' assumption that if the situation is threatening, but at the same time an effective strategy to reduce fear is available, fear will not persist [50]. Information about cancer or cancer symptoms may lead to increased fear, since many people associate cancer with death or unpleasant treatment. Providing effective strategies may help prevent fear. These strategies could include information about symptoms people should be attentive to, or information about adequate response to possible cancer symptoms. Since the control group in the present study was not given any potentially fear-inducing information, no changes in fear were expected, and indeed none found.

Some other issues should also be addressed in future research. First, the present study showed that it would be better to avoid different methods of collecting data, so as to enhance data comparability. We used written and telephone questionnaires. However, we assume that by using different kinds of data collection, the results may have been affected, since we expect that self-administered written questionnaires are less prone to social desirable answers than are telephone questionnaires. Nevertheless, we have chosen telephone questionnaires for the last post-test to enhance the response rate. Second, to avoid testing bias, an additional control group could be added at T2, which is not subjected to the pretest and the first post-test. Furthermore, we included people who voluntarily participated in our study. We realize that by voluntary enrolment, only those who were already interested in cancer were included in the sample. This may limit the generalizability of the results. An effort was made to reduce this problem by offering those participants who filled in all questionnaires a remuneration of EUR 45. Dijkstra et al. [51] suggested that offering a monetary incentive may attract different people and therefore limit selection bias. Although only those people who 
were interested in or open to information on early detection of cancer were recruited, this does not necessarily mean that we cannot generalize our results to a larger population. However, generalization is only possible to those people who are basically interested in cancer, considering that any kind of information only reaches those who are interested in the topic. A third issue to discuss concerns using intentions rather than behavior as the outcome variable. Unfortunately, we were not able to assess actual behavior, since the time frame was too short. To study actual passive detection and help-seeking behavior, a prospective study with a longer time frame, for instance, a 3-year follow-up, should be conducted. People could then be asked whether they have experienced possible cancer symptoms and how they responded to these symptoms. However, since intention is generally the most significant predictor of behavior [52], actual help seeking for cancer symptoms may be expected. Finally, it would be interesting to look at specific demographic groups, for instance, age groups or educational level, to determine whether the effects of the tailored intervention persist longer among certain groups. This information can be used to determine the types of setting for which this type of tailored information may be the most cost effective. However, the present study aimed to investigate the overall effects of the intervention rather than the effects for specific groups. This was done since in diffusion of interventions, it will not be possible to select specific target groups, so the general adult population will be approached.

\section{Implications for health education on early detection of cancer}

Although the short-term effects of the study were very much in favor of the tailored information, more research is needed to find out how the effects could be maintained in the long term and to study whether the effects of the tailored intervention may persist longer for certain demographic groups, for instance, for subjects of different age groups or educational level. To prevent a decline in intentions toward early detection of cancer in the long term, the effects of multiple tailoring on relevant aspects of early detection should be studied in greater detail. This could be done, for example, by progress or ipsative feedback, which provides feedback on the extent and direction of changes in variables relevant to the long-term effects of tailored information [22]. Positive results with this kind of feedback have been obtained [51,53]. Furthermore, it should be investigated whether a long-term decline in intentions could be avoided by, for instance, a non-tailored reminder to repeat the message or to maintain alertness. Positive results on compliance with BSE have been found for various prompts, such as telephone prompts, mailed prompts, personal prompts, or calendar stickers [54].

The encouraging results of the computer-tailored approach suggest that this method is a viable alternative to existing methods. The wide range of possibilities offered by this type of intervention allows it to be implemented in various settings, for instance, as a part of health education in the work place, by District Health Authorities, or by an annual mailing to benefactors of the Dutch Cancer Society. In The Netherlands, this was done with a smoking cessation program that was implemented on a national level by The Dutch Organization for Smoking Cessation [55], and a nutrition education program [48] by the District Health Authority.

The principles of tailoring can be applied in various interactive forms, such as CD-ROM, the Internet, or email, which has great potential in view of the rapid ICT developments. Further research should study how this relatively new approach in health education can be integrated into existing approaches. At present, it seems that mostly young people use the new media. This could offer a new tool to reach this specific target group, which is often difficult to reach for health education.

\section{Acknowledgment}

This study was supported by a grant from the Dutch Cancer Society.

\section{References}

[1] Ruwaard D, Kramers PGN, Volksgezondheid Toekomst Verkenning: De gezondheidstoestand van de Nederlandse bevolking in de periode 1950-2010 [Public health status and forecasts: The health status of the Dutch population over the period 1950-2010]. Den Haag: Elsevier/De Tijdstroom; 1997.

[2] Byles JE, Redman S, Hennrikus D, Sanson-Fischer RW, Dickinson J. Delay in consulting a medical practitioner about rectal bleeding. J Epidemiol Community Health 1992;46:241-4.

[3] Cassileth BP, Temoshok L, Frederick BEEA. Patient and physician delay in melanoma diagnosis. J Am Acad Dermatol 1988;18:591-8.

[4] Cochran SD, Hacker NF, Berek J. Correlates in delay of seeking treatment for endometrial cancer. J Psychosom Obstet Gynaecol 1986;5: $245-52$.

[5] Doherty VR, MacKie RM. Reasons for poor prognosis in British patients with cutaneous malignant melanoma. BMJ 1986;292:987-9.

[6] Lauver D, Chang CH. Explaining delay in care seeking for breast cancer symptoms. J Appl Soc Psychol 1993;23:106-25.

[7] Qin DX, Wang GQ, Zhang XH, et al. New concept for cancer screening. Eur J Cancer Prev 1996;5:121-4.

[8] Best DL, Davis SW, Vaz RM, Kaiser M. Testicular cancer education: a comparison of teaching methods. Am J Health Behav 1996; 20:229-41.

[9] Paskett ED, McMahon K, Tatum C, Velez R, Shelton B, Case LD, et al. Clinic-based interventions to promote breast and cervical cancer screening. Prev Med [doi:10.1006/pmed.1997.0254] 1998;27:120-8.

[10] Rakowski W, Ehrich B, Goldstein M, Rimer BK, Pearlman DN, Clark $\mathrm{MA}$, et al. Increasing mammography among women aged $40-74$ by use of a stage-matched, tailored intervention. Prev Med [doi:10.1006/ pmed. 1998.0354] 1998;27:748-56.

[11] Skinner CS, Strecher VJ, Hospers H. Physicians' recommendations for mammography: do tailored messages make a difference? Am J Public Health 1994;84:43-8. 
[12] Solomon LJ, Flynn BS, Worden JK, Mickey RM, Skelly JM, Geller $\mathrm{BM}$, et al. Assessment of self-rewarded strategies for maintenance of breast self-examination. J Behav Med 1998;21:83-102.

[13] Strickland CJ, Feigl P, Upchurch C, King DK, Pierce HI, Grevstad $\mathrm{PK}$, et al. Improving breast self-examination compliance: a Southwest oncology group randomized trial of three interventions. Prev Med [doi:10.1006/pmed.1997.0147] 1997;26:320-32.

[14] Rimer BK, Conaway M, Lyna P, Glassman B, Yarnall KSH, Lipkus I, et al. The impact of tailored interventions on a community health center population. Pat Educ Couns 1999;37:125-40.

[15] Mansson J, Marklunc B, Bengtsson C, Fridlund B. Evaluation of an educational programme for the early detection of cancer. Pat Educ Couns 1999;37:231-42.

[16] Dutch Cancer Society. Mijnheer, sommige kleinigheden kunt u maar beter niet negeren [You would do better not to ignore some physical complaints, sir]. Amsterdam: Dutch Cancer Society; 1998.

[17] Sarafino EP. Health psychology. Biopsychosocial interactions. . New York: Wiley; 1998.

[18] Olson KL, Morse JM. Explaining breast self-examination practice. Health Care Women Int 1996;17:575-91.

[19] Hobbs P, Haran D, Pendleton LL, Jones BE, Posner T. Public attitudes and cancer education. Int Rev Appl Psychol 1984;33:565-86.

[20] Weist MD, Finney JW. Training in early cancer detection and anxiety in adolescent males: a preliminary report. Dev Behav Pediatr 1996;17: $98-9$.

[21] De Vries H, Brug J. Computer-tailored interventions motivating people to adopt health promoting behaviours: introduction to a new approach. Pat Educ Couns 1999;36:99-105.

[22] Dijkstra A, De Vries H. The development of computer-generated tailored interventions. Pat Educ Couns 1999;36:193-203.

[23] Kreuter MW, Strecher VJ, Glassman B. One size does not fit all: the case for tailoring print materials. Ann Behav Med 1999;21:276-83.

[24] Petty RE, Cacioppo JT. The elaboration likelihood model of persuasion. In: Berkowitz L, editor. Advances in experimental social psychology. London: Academic Press; 1986. pp. 123-205.

[25] Brug J, Campbell M, Assema P. The application and impact of computer-generated personalized nutrition education: a review of the literature. Pat Educ Couns 1999;36:145-56.

[26] Campbell MK, DeVellis BM, Strecher VJ, Ammerman AS, DeVellis RF, Sandler RS. Improving dietary behavior: the effectiveness of tailored messages in primary care settings. Am J Public Health 1994;84: $783-7$.

[27] Dijkstra A, De Vries H, Roijackers J. Long-term effectiveness of computer-generated tailored feedback in smoking cessation. Health Educ Res 1998;13:207-14.

[28] Strecher VJ, Kreuter MW, Boer DD, Kobrin SC, Hospers HJ, Skinner CS. The effects of computer tailored smoking cessation messages in family practice settings. J Fam Pract 1994;39:262-70.

[29] Kreuter MW, Bull FC, Clark EM, Oswald DL. Understanding how people process health information: a comparison of tailored and nontailored weight-loss materials. Health Psychol 1999;18:487-94.

[30] Bull FC, Kreuter MW, Scharff DP. Effects of tailored, personalized and general health messages on physical activity. Pat Educ Couns 1999;36:181- 192 .

[31] Kreuter M, Farrell D, Olevitch L, Brennan L. Tailoring health messages. Customizing communication with computer technology. Mahwah, New Jersey: Lawrence Erlbaum Associates; 2000.

[32] Rhodes F, Fishbein M, Reis J. Using behavioral theory in computerbased health promotion and appraisal. Health Educ Behav 1997;24: $20-34$.

[33] De Vries H, Dijkstra M, Kuhlman P. Self-efficacy: the third factor besides attitude and subjective norm as a predictor of behavioral intentions. Health Educ Res 1988;3:273-82.

[34] De Vries H, Backbier E, Kok G, Dijkstra M. The impact of social influences in the context of attitude, self-efficacy, intention, and pre- vious behavior as predictors of smoking onset. J Appl Soc Psychol 1995;25:237-57.

[35] Ajzen I. The Theory of Planned Behavior. Org Behav Hum Decis 1991;50:179-211.

[36] Lechner L, De Vries H, Offermans N. Participation in a breast cancer screening program: influence of past behavior and determinants on future screening participation. Prev Med [doi:10.1006/pmed.1997. 0161] 1997;26:473-82.

[37] De Nooijer J, Lechner L, De Vries H. Social psychological correlates of paying attention to cancer symptoms and seeking medical help. Soc Sci Med 2003;56:915-20.

[38] Lechner L, Oenema A, De Nooijer J. Testicular self-examination (TSE) among Dutch young men aged 15-1; determinants of the intention to practice TSE. Health Educ Res 2002;17:73-84.

[39] Brug J, Lechner L, De Vries H. Psychosocial determinants of fruit and vegetable consumption: telephone survey. Appetite 1995;25: $285-96$.

[40] Lechner L, DeVries H, Participation in an employee fitness program: determinants of high adherence, low adherence and dropout. J Occ Environ Med 37 429-436

[41] Willemsen MC, De Vries H, Van Breukelen G, Oldenburg B. Determinants of intention to quit smoking among Dutch employees: the influence of the social environment. Prev Med 1996;25:195-202.

[42] Lechner L. Social psychological determinants of health risk behaviors related to cancer and CVD: applications and elaborations of the ASE model. Health education and promotion. Maastricht: Universiteit Maastricht; 1998. p. 211

[43] Berman SH, Wandersman A. Measuring knowledge of cancer. Soc Sci Med 1991;32:1245-55.

[44] Jepson C, Chaiken S. Chronic issue-specific fear inhibits systematic processing of persuasive communications. J Soc Behav Pers 1990;5: $61-84$.

[45] De Nooijer J, Lechner L, De Vries H. Tailored vs. general information on early detection of cancer: a comparison of the reactions of Dutch adults and its impact on attitudes. Health Educ Res 2002;17:239-52.

[46] Dutch Cancer Society. Wees wijzer, van doorlopen met klachten wordt u zeker niet beter [Be wise: living with complaints won't make you any better]. Amsterdam: Dutch Cancer Society; 1991.

[47] Tabachnick BG, Fidell LS. Using multivariate statistics. New York: HaarperCollins College Publishers, 1996.

[48] Brug J, Steenhuis IHM, Van Assema P, De Vries H. The impact of a computer-tailored nutrition intervention. Prev Med [doi:10.1006/ pmed.1996.0052] 1996;25:236-42.

[49] Green LW, Lewis FM. Measurement and evaluation in health education and health promotion. Palo Alto, CA: Mayfield Publishing Company; 1986

[50] Rogers RW. Cognitive and physiological processes in fear appeals and attitude change: a revised theory of protection motivation. In: Cacioppo JT, Petty RE, editors. Social psychophysiology—A source book. New York: Guilford Press; 1983. p. 153-76.

[51] Dijkstra A, De Vries H, Roijackers J, Van Breukelen G. Tailoring information to enhance quitting in smokers with low motivation to quit: three basic efficacy questions. Health Psychol 1998;6:513-9.

[52] Godin G, Kok G. The Theory of Planned Behavior: a review of its applications to health-related behaviors. Am J Health Promot 1996;11:87-98.

[53] Brug J, Glanz K, Van Assema P, Kok G, Van Breukelen GJP. The impact of computer-tailored feedback and iterative feedback on fat, fruit, and vegetable intake. Health Educ Behav 1998;25:517-31.

[54] Clarke VA, Savage SA. Breast self-examination training: a brief review. Cancer Nursing 1999;22:320-6.

[55] Willemsen M. Personal communication; 2001.

[56] Dutch Cancer Society. Vroege ontdekking van kanker... wat u zelf kunt doen [Early detection of cancer... what can you do]. Amsterdam; 1996 